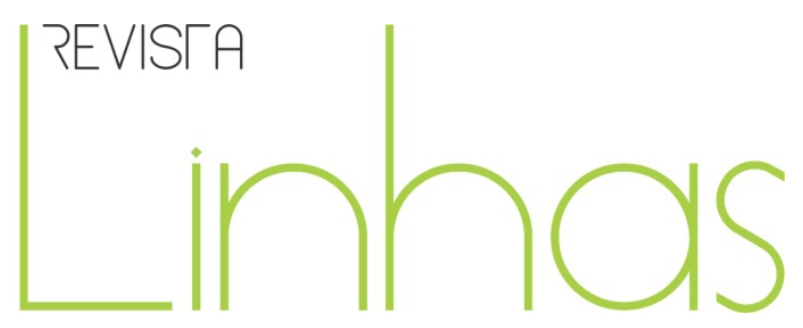

\title{
A constituição de um novo paradigma das ciências sociais. Observações teórico-metodológicas sobre "Les Héritiers"
}

\section{Resumo}

Pretende-se, no presente texto, estabelecer algumas observações teórico-metodológicas acerca da obra Les Héritiers, de Bourdieu e Passerron, publicada em 1964, como compartilhando a mesma concepção de ciência que Le Métier de Sociologue, originalmente publicado em 1968. Para tanto, o texto é disposto de acordo com a seguinte estrutura: em primeiro lugar, discutem-se a concepção de educação e escola que estão presentes em Durkheim; em segundo lugar, aborda-se a sociologia francesa de meados do Século XX, dando especial atenção ao hiperfuncionalismo de Parsons; em terceiro lugar, discutem-se os aspectos teóricos e metodológicos de Les Héritiers e a ideia de ciência apresentada em Le Métier de Sociologue como sendo compartilhada por Les Héritiers.

Palavras-chave: Os Herdeiros; Epistemologia das Ciências Sociais; Ciência; Bourdieu; Passeron.

\author{
Marcos Rohling \\ Doutorando pelo Programa de \\ Pós-graduação em Educação \\ (PPGE) da Universidade Federal \\ de Santa Catarina - UFSC - Brasil \\ marcos_roh@yahoo.com.br
}

\section{Para citar este artigo:}

BASTOS, Maria Helena Camara; JACQUES, Alice Rigoni. Liturgia da memória escolar - Memorial do Deutscher Hilfsverein ao Colégio Farroupilha (2002). Revista Linhas. Florianópolis, v. 15, n. 29, p. 270-296, jul./dez. 2014.

\section{DOI: $10.5965 / 1984723815292014270$}

http://dx.doi.org/10.5965/1984723815292014270 


\title{
The constitution of a new paradigm of social sciences. Remarks methodological theoretical on "Les Héritiers"
}

\begin{abstract}
It is intended, in this text, establish some theoretical and methodological remarks about the work Les Héritiers' Bourdieu and Passerron, published in 1964, as sharing the same conception of science that Le Métier of Sociologue, originally published in 1968. To this end, the text is arranged according to the following structure: first, it discuss the design of education and school that are present in Durkheim; secondly, it explain about the French sociology of midtwentieth century, with special attention to Parsons' hiperfucionalism; third, it discuss the theoretical and methodological aspects of Les Héritiers and the sciense's idea belonging in Le Métier Sociologue as being shared by Les Héritiers.
\end{abstract}

Keywords: The Inheritors; Epistemology of the Social Sciences; Sciense; Bourdieu; Passeron. 


\section{Introdução}

No plano da análise, a obra Les Héritiers. Les Étudiants et la Culture (BOURDIEU e PASSERON, 1964) ${ }^{1}$ empreendeu uma poderosa crítica ao sistema de ensino francês, desde a educação básica até o acesso ao ensino superior, desvelando as desigualdades que caracterizavam a educação francesa. Tratava-se de desmontar o mito da escola republicana libertadora, nos termos de um instrumento político de democratização e de promoção da mobilidade social, uma vez que, através de análises amparadas em dados as quais revelavam, à época, um novo modus operandi -, mostrou-se que a perpetuação das desigualdades, em face da cultura, predominava nos processos de escolarização mediante os recursos pedagógicos e avaliativos que transformavam privilégios sociais em méritos, dons e talentos individuais. Dessa maneira, os diversos modos de desigualdades, advindas das diferentes formas de relacionamentos com a cultura, legitimavam as próprias desigualdades: é a tese de que herança cultural, cristalizada na educação escolar, exerce um papel fundamental na reprodução social (VALLE, 2014, p. 9).

O texto de Bourdieu e Passeron, Les Héritiers, marca um ponto de mudança ou de inovação radical na sociologia da educação na França, que, apesar de recuperar a tradição de Durkheim consoante à retomada da centralidade da educação no sentido de nucleá-la em torno da sociologia, difere dos projetos durkheimianos que consideram a escola como fonte de integração institucional, de socialização, autonomia e mobilidade social. De fato, o tema de Les Héritiers, a desigualdade de acesso dos estudantes ao ensino superior de acordo com a sua origem social, está associada a uma análise centrada sobre o privilégio cultural que atribui à escola um papel importante na reprodução das desigualdades.

Nesse sentido, a produção de Les Héritiers, representando uma ruptura epistemológica no plano da metodologia, que, desde a metade do século XX, marca profundamente as ciências sociais, especialmente aquelas praticadas em países cujas raízes são claramente remetidas às fontes francesas do pensamento sociológico, permite ver uma ligação entre Le Métier de Sociologue (BOURDIEU, CHAMBOREDON e PASSERON,

\footnotetext{
${ }^{1}$ Tradução brasileira: Os Herdeiros: os Estudantes e a Cultura. Trad. Ione R. Valle e Nilton Valle. Florianópolis: Ed. da UFSC, 2014.
} 
$1968)^{2}$, como um manifesto de escola, isto é, da sua própria teoria do mundo social. ${ }^{3}$ Os princípios de uma postura científica que implica, por um lado, o rompimento com o senso comum e, por outro, a construção do fato social, afirmados como próprios da sociologia científica, caracterizam a metodologia empreendida em Les Héritiers. Valendo-se do recurso de dados estatísticos, os autores empreendem esforços na direção da mensuração da desigualdade de acesso à educação superior considerando, sobretudo, a origem social e o sexo, a partir da análise das atitudes dos alunos e dos professores. Dessa maneira, esse modus operandi científico estabeleceu, nos termos de Kuhn, um novo paradigma ${ }^{4}$ no que se refere ao conhecimento e método sociológicos, a saber: as leis da reprodução as quais colocam a escola no centro da estrutura de reprodução social.

Pretende-se, neste texto, oferecer uma reflexão a partir dos aspectos teóricometodológicos de Les Héritiers que podem ser vinculados a Le Métier de Sociologue. Tratase de analisar aspectos relacionados ao seu contexto de elaboração, bem como influências teóricas e conceituais que contribuíram para a sua constituição e que apresentam em Le Métier de Sociologue uma descrição da atividade científica do sociólogo, mormente, o sociólogo da educação. Em outras palavras, que nos dois ensaios se opera a mesma concepção de ciência (ROBBINS, 1998, p. 35). Para tanto, o texto é disposto de acordo com a seguinte estrutura: em primeiro lugar, argumenta-se sobre a

\footnotetext{
${ }^{2}$ Tradução brasileira: A Profissão de Sociólogo. Preliminares Epistemológicas. Trad. Guilherme J. de Freitas Teixeira, $3^{a}$. Ed. Petrópolis: Vozes, 2002.

${ }^{3}$ É importante que se diga: Le Métier de Sociologue é uma obra rubricada a seis mãos. Diferentemente dos demais autores, entre os quais Passeron, que consideravam a teoria sociológica ali presente em sentido fraco, de modo a ser partilhada por uma pluralidade de teorias que se pretendessem sociológicas, Bourdieu compreendeu tal manual, desde o início, como um manifesto de escola do modo como entendia ser o mundo social (VANDENBERGHE, 1999, p. 37).

${ }^{4} \mathrm{O}$ termo paradigma, como se disse, é usado no mesmo sentido que Kuhn atribuiu a ele em A Estrutura das Revoluções Científicas, publicada em 1962. De acordo com Kuhn, que tem grande influência de Bachelard, para que se compreenda a natureza da ciência, o cientista ou pesquisador da história da ciência deve focar a sua atenção nas comunidades científicas: são elas os verdadeiros sujeitos da ciência, em que pese que a ciência é praticada através de disciplinas, as quais, por sua vez, dependem do consenso dos pesquisadores sobre o que faz da sua disciplina o que ela é. Com efeito, tal consenso é proveniente de alguma obra que logra tal concordância (como é o caso da Física, de Aristóteles) tendo em vista constituir-se por certo período de tempo em modelo para a atividade científica. O consenso em torno da referência, contudo, obtém-se em função de duas características principais, notadamente, (i) a de resolver convincentemente problemas importantes para a comunidade científica, de determinada área, e, (ii) deixar outros problemas em aberto os quais podem ser resolvidos conforme o modelo proposto pela obra referência, instituindo uma ciência normal. Brevemente, essa é a caracterização de um paradigma: conjunto de práticas, crenças, valores e técnicas que são reconhecidos como adequados por uma comunidade científica (KUHN, 1978, p. 30).
} 
questão do método nas ciências sociais, especialmente, aquela em evidência em meados do século XX e, no interior da qual, os autores vão afirmar os pressupostos científicos da sua sociologia; em segundo lugar, traçam-se as linhas mais identitárias das categorias e da sociologia formulada por Bourdieu, o qual, cada vez mais, parece assumir a paternidade intelectual de tal obra; em terceiro lugar, por fim, analisa-se mais detidamente Les Héritiers no que se refere aos seus aspectos teóricos e metodológicos à luz de Le Métier de Sociologue. Como efeito, espera-se demonstrar o vínculo conceitual entre tais obras, e, assim, que tanto a concepção quanto o sentido das categorias de análise empregadas por Bourdieu nas análises sociológicas foram se modificando significativamente nas últimas décadas, até as produções mais relevantes dos seus últimos anos de vida.

\section{As diferenças em relação à Durkheim: da educação à concepção de escola}

Les Héritiers é uma obra que rompe com a tradição francesa de Durkheim, no que se refere à compreensão da escola. No projeto sociológico de Durkheim, a escola é vista como fonte de integração institucional de socialização, autonomia e mobilidade social. ${ }^{5}$ Assim cotejada, a escola adquire centralidade na análise de Durkheim justamente por promover o processo por meio do qual o indivíduo é integrado à sociedade. E, como se pode apreciar, considerando que o fim da educação é o desenvolvimento em cada indivíduo da perfeição que é capaz, Durkheim afirma a sua dependência da sociedade a que está restrita. Para o sociólogo,

\footnotetext{
${ }^{5}$ Num artigo dedicado aos aspectos que aproximam Bourdieu e Durkheim, Wacquant afirma logo no início que um estudo que desse conta dessa empreitada demandaria uma monografia histórico-analítica capaz de reconstruir o duplo encadeamento, social e conceptual, das causalidades emaranhadas que os vinculavam um ao outro e aos seus respectivos meios. Ele propõe, então, que é possível estabelecer a base comum sobre a qual estariam assentadas as obras desses dois sociólogos, a saber: (i) a adesão ferrenha ao racionalismo; (ii) a recusa da teoria pura e a defesa obstinada da indivisão da ciência social; (iii) a relação com a dimensão e a disciplina históricas; e, por fim, (iv) o recurso à etnologia como dispositivo privilegiado de 'experimentação indireta'. Esses seriam, portanto, os quatro pilares que permitiriam uma base comum entre esses sociólogos. Cf. WACQUANT, 1997, p. 29. Embora se pudesse desenvolver um texto com uma finalidade mais comparativa entre esses autores, não é o que se pretende fazer aqui. A recuperação das ideias de Durkheim cumpre apenas a finalidade de recuperar o terreno do qual Bourdieu e Passeron partiram para suas análises.
} 
A educação é a ação exercida pelas gerações adultas sobre aquelas que ainda não estão maturas para a vida social. Ela tem como objetivo suscitar e desenvolver na criança um certo número de estado físicos, intelectuais e morais exigidos tanto pelo conjunto da sociedade política quanto pelo meio específico ao qual ela está destinada em particular. (DURKHEIM, 2011, p. 53-54)

À educação, então, cumpre formar um indivíduo que tomará parte na vida social, conduzindo-o até que seu ser social esteja formado, através da transmissão das ideias de moral, hábitos e sentimentos, de modo a tornar-se apto para viver em sociedade. Essa forma de entender a ação da educação, tomada genericamente, conforme aponta Steiner (1994), tem uma dupla natureza: de um lado, significa disciplina, acima de tudo, uma vez que o indivíduo deve obrigar os sentimentos egoístas que carrega dentro de si naturalmente; e de outro, essa disciplina, esse constrangimento social, não é, todavia, pouco atraente porque ele só permite que o indivíduo enfatize o que há de melhor nele, no sentido de que forme o seu ser social que repudia o egoísmo próprio dos animais. (STEINER, 1994, p. 94-95). Não obstante, para Durkheim a educação é um elemento essencial da socialização, pois que ensina ao indivíduo as regras pelas quais a sua conduta será adaptada a uma vida social altamente desejável (STEINER, 1994, p. 95).

Uma vez que a importância social da educação tenha ficado evidente, Durkheim argumenta no sentido de especificar o papel do Estado em termos de matéria educacional. Para ele, já que em virtude da sua importância, o Estado não pode se desinteressar da educação, tudo o que está relacionado à educação deve estar submetido à sua ação. Isso implica o oferecimento de instituições educacionais, muito embora não seja necessário que o Estado monopolize o ensino, as quais devem necessariamente proporcionar uma formação consonante com os princípios e valores sociais. Entre esses valores, que devem ser reconhecidos por todos, fundamentalmente pelo Estado, Durkheim (2011, p. 63-64) nomeia o respeito da razão, da ciência e das ideias e sentimentos que sustentam a moral democrática. A educação e as instituições que dela fazem parte teriam, assim, um compromisso com os valores próprios à vida democrática. 
Na análise que Bourdieu e Passeron desenvolvem em Les Héritiers, os autores creditam à escola um papel muito diverso daquele que Durkheim havia concebido. Enquanto que, para o pai da sociologia científica a escola é vista como vital no processo de socialização e integração do indivíduo ao meio social, para os primeiros a escola está especialmente relacionada às formas de reprodução social. Isso significa dizer que a desigualdade de acesso ao ensino superior por parte dos estudantes, conforme a origem social, está fundamentalmente associada ao privilégio cultural, o qual, por sua vez, reconhecendo na escola a instituição primordial para reprodução das assimetrias sociais, apenas prolonga as desigualdades que antecedem a vida acadêmica.

Dessa feita, os autores atacam o discurso recorrente de que a escola é disponibilizada para todos igualmente e que, através dela, seria possível a realização das potencialidades humanas, pondo em destaque que a instituição escolar mascara sob a sua aparência de neutralidade. É o que Rodrigues quer dizer ao explicar como se deu tal crítica por parte dos autores:

[...] colocando em evidência o que a instituição escolar dissimula por trás de sua aparente neutralidade, ou seja, justamente a reprodução das relações sociais e de poder vigentes. Encobertos sob as aparências de critérios puramente escolares, estão critérios sociais de triagem e de seleção dos indivíduos para ocupar determinados postos na vida. (RODRIGUES, 2004, p. 85)

Como se pode apreciar, procedendo desse modo, em Les Héritiers, os autores rompem drasticamente com o ideal de escola pautado em valores democráticos, o qual, em instância, é remetido às elaborações do próprio Durkheim. Como é evidente, os autores tinham em mente um projeto crítico audacioso. No que se segue, dar-se-á mais atenção aos aspectos teóricos e metodológicos que aproximam tal obra às investiduras teóricas de Le Métier de Sociologue. 


\section{A sociologia da educação francesa da primeira metade do século xx: o predomíno do hiperfuncionalismo}

$\mathrm{Na}$ França, a sociologia da educação é devedora inevitavelmente das contribuições de Durkheim, para o qual, como fenômeno social, a educação é por excelência o objeto da sociologia, tendo em vista a sua importância no processo de socialização. Embora a escola tenha sido objeto de estudo de diferentes domínios científicos que não apenas aqueles da sociologia, foi principalmente após a Segunda Guerra Mundial que a sociologia da educação tomou a escola para investigação científica: ou seja, abandonou o caráter filosófico-sociológico, característico do final do século XIX até o entreguerras, no qual estava restrita aos manuais didáticos e às reflexões mais generalistas a respeito da educação na sociedade. Assim considerando, como campo científico que assume a educação, a escola e todas as instituições que estão envolvidas nos processos educacionais, foi apenas a partir dos anos 60 que a sociologia emergiu como um saber distinto (CUNHA, 2010, p. 17-18).

É imperioso ter presente que o processo de modernização dos sistemas educacionais, em quase todos os países europeus, a partir do final dos anos 50 e durante os anos 60, passou a fazer parte das agendas políticas, e acompanhou o período de crescimento econômico acelerado que se seguiu à reconstrução da economia européia no pós Segunda Guerra Mundial. Consoante com o modelo de sociedade funcionalisticamente entendida, a educação seria de tal modo que corrigiria as desigualdades sociais, de forma a promover uma política educacional fundada na ideia da promoção da igualdade social (NOGUEIRA, 1990, p. 51-52). ${ }^{6}$

Mais claramente, pode-se falar de dois momentos relevantes particularmente para a sociologia da educação em terreno francês: (a) o primeiro deles, compreende o período que vai de Durkheim, visto como o pai da sociologia da educação, até em torno da Segunda Guerra Mundial; (b) o segundo deles, é posterior à Segunda Guerra Mundial,

\footnotetext{
${ }^{6}$ Segundo esta perspectiva, pode-se dizer que essa modernização dos sistemas de ensino, em face do desenvolvimento econômico, deu-se em virtude da necessidade da mão de obra mais qualificada e de uma população com nível de formação elevado. No âmbito das pesquisas educacionais, este período foi marcado pela produção de vários relatórios de pesquisa financiados pelo Estado em diversos países e marcou uma fase que via a educação como sinônimo de desenvolvimento econômico.
} 
passando por Bourdieu, até os dias de hoje, no qual se destaca principalmente François Dubet. Nesse primeiro momento, a sociologia da educação é especialmente marcada por três características, a saber: (i) ausência de investigação empírica, tendo em vista que os estudos estavam mais preocupados com os grandes modelos de análise estatística, ancorados numa tradição mais quantitativa, e nos quais os sujeitos quase não apareciam; (ii) a sociologia praticada é macroscópica, dificultando a investigação sobre o que acontecia no interior da escola; e (iii) a sociologia é reduzida a uma matéria de ensino, de modo a não se constituir num campo de pesquisa, estabelecia-se mais como uma tradição histórico-filosófica (CUNHA, 2010, p. 19).

De modo geral, no primeiro momento referenciado, os sujeitos da sociologia da educação são praticamente uma categoria abstrata, já que a amostra quantitativa, própria da presença positivista, é que tem validade. Nesse sentido, são os dados estatísticos que importam, e, claramente, são eles que formam e estabelecem os entendimentos a respeito dos sujeitos da educação. Trata-se, assim, de um modelo mais distante da dinâmica interna ao processo educativo do qual a escola e as demais instituições educacionais fazem parte.

No segundo momento, tem-se aquilo que é conhecido como institucionalização da sociologia da educação como um domínio de conhecimento científico no interior da sociologia, principalmente a partir da influência da sociologia de Talcott Parsons. Entre os acontecimentos históricos ocorridos nesse período, encontra-se a chamada explosão demográfica, que se caracteriza pela recomposição das famílias após o término da guerra e pelo ingresso das mulheres no mercado de trabalho, de modo a se ter uma prosperidade econômica. Esses acontecimentos refletiram-se na educação através das políticas de acesso - a chamada explosão escolar como consequência da universalização do ensino -, calcadas em valores democráticos, em larga medida, baseadas tanto na sociologia de Durkheim, quanto naquela de Parsons (CUNHA, 2010, p. 19). Nogueira lembra que, as mudanças pós-guerra provocaram o aparecimento de uma corrente de pesquisa educacional que foi chamada de 
[...] empirismo metodológico (thodological empiricism) por tratar-se de investigações empíricas - freqüentemente quantitativas - cujo esmero metodológico quase sempre conotou rigor, à época. As preferências, quanto ao objeto da pesquisa, recaíam - como bem convinha à época sobre as desigualdades educacionais e sobre a problemática da democratização do ensino. Calculava-se assim as taxas de escolarização segundo as categorias sócio-econômicas; estabelecia-se correlações entre o desempenho escolar e uma série de fatores sociais tais como: idade, sexo, habitat, profissão e nível escolar dos pais, tamanho da família etc; buscava-se identificar os elementos responsáveis pela carência cultural das crianças e jovens provenientes dos grupos sociais desfavorecidos para se chegar a soluções compensatórias. É quase desnecessário lembrar que tais estudos situam-se num nível macroscópico de análise, em que o que se focaliza são as grandes relações entre o sistema educacional e as outras instituições sociais; não se entrando, portanto, no interior dos processos de ensino (estabelecimento escolar, sala de aula etc). (NOGUEIRA' ${ }^{1} 990$, p. ${ }^{54}$, o negrito é da autora)

A teoria parsonsiana, uma das grandes influências sociológicas desse período, por sua vez, era adepta da seleção escolar baseada nas habilidades e no aproveitamento escolar diferenciado. Nesta forma de compreender a sociedade, o sistema escolar assim orientado, seria responsável pela preparação dos indivíduos tendo em vista ocuparem postos sociais hierarquizados, com a finalidade da manutenção do equilíbrio harmonioso da sociedade. Como recordam Valle e Ruschel (2010, p. 79), na perspectiva de Parsons,

[...] o compartilhamento de valores comuns, a adesão de todos à ideologia do mérito individual e à crença na igualdade das oportunidades permitirão, numa sociedade competitiva e aberta, superar a frustração decorrente do fracasso. A "competição meritocrática" supõe a existência de ganhadores e de perdedores, mas para que a coesão social continue possível é necessário, antes de tudo, que todos reconheçam como eqüitativas as regras do jogo e sejam persuadidos de que as vantagens conquistadas por cada um refletem as diferenças interindividuais de talento e mérito [...].

Isso se explica porque Parsons era representante, em sociologia, da corrente estrutural-funcionalista, que defendia uma visão concomitantemente sistêmica e funcionalista da sociedade. Tal visão implicava que, para que ela pudesse existir estavelmente, precisaria responder a diversas funções, tais como, a adaptação ao meio 
que assegura a sobrevida da sociedade, a busca por objetivos, a integração de membros do grupo, a manutenção de modelos e de normas, entre outras coisas. Dentro desse modelo, Parsons observa que a educação, entendida como socialização, é o mecanismo básico de constituição dos sistemas sociais e de manutenção e perpetuação dos mesmos, em formas de sociedades. Assim, sem a socialização, o sistema social seria ineficaz na direção da manutenção da integração, da ordem e do equilíbrio (PARSONS, 2010, p. 410436).

É a partir desse modelo que Parsons procura explicar as diferentes instituições sociais: objetiva perscrutar as suas funções e lógicas internas. Na análise que faz, os sistemas são abertos e evolutivos, desde que existam os mecanismos de regulação econômica ou social. Assim, no pós-guerra, ele procurou responder à questão de como se pode compreender uma ordem social organizada num país livre e no qual as pessoas escolhem livremente suas atividades, principalmente, porque a sociedade estadunidense de então desfrutava de franco crescimento e de considerável integração social. Em virtude disso, preocupou-se com um modelo de educação fundamentado na ideia de oferecer a todos a mesma igualdade de oportunidades, a qual recompensaria as pessoas conforme o esforço e o mérito proporcionando-lhes as melhores chances e funções mais nobres na hierarquia social (CUNHA, 2010, p. 20).

As discussões e as obras produzidas nesse domínio do conhecimento sociológico, a partir dos anos 60, em geral, assumiram um discurso crítico que atacava a visão naturalista dos dons e habilidades, fortes marcadores da teoria durkheimiana, e que fora avivada pela teoria do sociólogo americano Talcott Parsons. Através de um viés mais crítico e desencantado que estabelece um novo paradigma no interior das ciências sociais, as análises de Bourdieu e Passeron demonstraram, inicialmente em Les Héritiers, em seguida em La Reproduction e, mais tarde, apenas por Bourdieu em Homo Academicus, que as instituições escolares são marcadas pelas desigualdades e por mecanismos de reprodução que prolongam privilégios oriundos da vida pregressa à vivência escolar dos estudantes. A teoria da reprodução anunciada pelos sociólogos compreende que a ação pedagógica, por meio da função de reprodução cultural, perpetua o arbitrário cultural que é responsável pela produção, reprodução e legitimação das desigualdades sociais. 
Assim, o sistema de ensino teria uma dupla função: inculcação e reprodução de um arbitrário cultural. Neste contexto, a ação pedagógica aparecia condenada de início, já que os mecanismos presentes no sistema escolar acabam por reproduzir a divisão social imposta em uma sociedade de classes.

\section{Elementos teórico-metodológicos de Les Héritiers, Les Étudians et la Culture}

A sociologia de Bourdieu é resultado de um processo caracterizado por muitas rupturas e mudanças, ao longo de, pelo menos, cinco décadas. Um desses momentos afirmados é aquele da elaboração, em parceria com Jean-Claude Passeron, de Les Héritiers, Les Étudiants et la Culture. ${ }^{7}$ Isso quer dizer que os pressupostos epistemológicos afirmados como científicos, assim como as categorias com as quais o real é analisado, no quadro geral da sociologia bourdieusiana, estavam ainda em formação. É verdade que Les Héritiers é uma obra conjunta e, portanto, de concepções e categorias partilhadas pelos dois autores, ao menos, até aquele momento. ${ }^{8}$ Com efeito, seguindo a trilha de Sidicaro, esta obra se converteu num clássico da sociologia que interessa tanto por conta de seu conteúdo, quanto pela estratégia analítica que propõe. Esta afirmação é clara quando se observa a ruptura nela inaugurada pelos sociólogos:

[...] a combinação presente nesse texto de formas rigorosas de investigação empírica com uma reflexão conceitual, que se insere as análises numa teoria inovadora sobre as sociedades modernas e seus conflitos, motivou a sua atração. Os estudos sobre os sistemas escolares e as práticas culturais, temas prediletos das primeiras investigações do grupo formado em torno de Bourdieu, romperam com os enquadramentos habituais para tratar essas questões ao remeter as explicações à dinâmica do conjunto da sociedade e, mais especificamente, aos mecanismos de violência simbólica que legitimam as relações de dominação e de desigualdade social. (SIDICARO, 2009, p. $\mathrm{X}$, tradução minha)

\footnotetext{
${ }^{7}$ Sobre a parceria dos autores, ver: Bruno (2009, especialmente páginas 08 a 10).

${ }^{8}$ Sobre esse ponto, ver: Passeron (2004, p. 369-403).
} 
Assim disposta, Les Héritiers representou uma crítica contumaz no sentido de que levou a todos os âmbitos da vida social uma visão crítica a respeito dos domínios nos quais se assentavam significativas expectativas sociais e individuais, notadamente, as instituições de ensino, as quais, até então, eram vistas sob a crença compartilhada de que se tratavam de instâncias a serviço do interesse geral ou de que favoreceram o progresso de todos por igual (SIDICARO, 2009, p. IX). Na interpretação que aqui se faz pode-se, evidentemente, afiançar os elementos teóricos característicos da compreensão da sociologia como ciência podem ser encontrados na obra Le Métier de Sociologue, que, além dos dois autores, é também rubricada por Jean-Claude Chamborredon.

As teses esboçadas por Bourdieu e Passeron, em Les Héretiers, que estabelecem uma visão crítica e desencantada da escola, são baseadas numa concepção de ciência social em oposição àquela predominante, mais vinculada aos dados quantitativos e sem análises mais próximas do interior das realidades estudadas, na qual o método e o objeto são vistos como reinantes. Nesse sentido, pode-se dizer que as teses quanto à cientificidade das ciências sociais são aquelas que aparecerão, pouco tempo depois, em Le Métier de Sociologue, de modo a se ter uma mesma concepção de ciência. Além disso, convém ressaltar que, à época da elaboração do livro, na França, além do hiperfuncionalismo de Parsons, duas outras tendências estavam em evidência: em primeiro lugar, a quantophrénie de enquetes sociológicas fortemente baseadas no método definido por Lazarsfeld, ainda era muito presente, embora já muito criticada ${ }^{9}$, e, em segundo lugar, o estruturalismo, que apesar da influência, sob certos vieses, sobre o pensamento de Bourdieu, como uma escola de pensamento não fez parte das influências determinantes para a elaboração de Les Héritiers (BRUNO, 2009, p. 24-36).

A sorte inicial de um escrito como esse encontrou públicos ao mesmo tempo distintos e com expectativas contraditórias, por razões como as que se seguem: no movimento estudantil de maio de 1968, muitos leitores interpretaram o livro como um modo de denunciar o sistema escolar e universitário francês, que era desigual no que se

\footnotetext{
${ }_{9}^{9}$ Sobre a relação de Bourdieu e Lazarsfeld, recomenda-se o seguinte texto: Baranger (2010, especialmente a primeira parte).
} 
refere ao acesso ao ensino superior, beneficiando os filhos dos setores privilegiados em detrimento dos das camadas populares. Como se indicou anteriormente, mas que vale a pena recordar, tratava-se de um contexto de crescimento do ensino superior e de desenvolvimento das primeiras análises sobre as desigualdades escolares: a geração do baby boom que entra no ensino secundário e superior, cujos números se tinham mantidos estáveis na primeira metade do século XX, as primeiras reformas institucionais de Charles de Gaulle que elevam as matrículas - extensão da escolaridade obrigatoriedade de 14 para 16 anos, em 1959, sob a crença de que era necessário formar uma elite científica e tecnológica mais numerosa para expandir o poder econômico - e um notável aumento na demanda de famílias, as quais projetavam na educação a esperança de mobilidade social (WEBER, 2011, p. 23).

Juntando-se a esses aspectos históricos e teóricos, também contribui para o sucesso da obra aquilo que Gremion (2005) denomina de dimensão da estrutura intelectual. Conforme este autor, o sucesso do livro depende de três elementos: um explícito, outro implícito e, por fim, um terceiro oculto. O primeiro elemento, que é explícito, é a referência a Weber. Isso talvez possa ser explicado em virtude de que, naquele tempo, Bourdieu era membro do centro dirigido por Raymond Aron, cujas ascendências teóricas estavam afinadas com a teoria de Weber. O segundo elemento, que se encontra implícito, o qual embora não seja citado é o mais prevalente, é a presença da teoria de Marx. Tal presença pode ser cotejada especialmente sob o viés do uso do conceito de ideologia em sua forma canônica. Por fim, o terceiro elemento, que está oculto, é aquele da tradição durkheimiana. Ao colocarem a questão da educação no centro da sociologia, Bourdieu e Passeron retomam esta tradição, que perdeu força após a Segunda Guerra Mundial (conforme já indicado). ${ }^{10}$

A partir das enquetes que formam o núcleo empírico de Les Héritiers, Bruno argumenta que tal obra é, de algum modo, resultado de pesquisas iniciadas muito antes. Os trabalhos anteriores de Bourdieu e Passeron sobre a crise universitária, os primeiros relatórios concernentes às enquetes sobre os estudantes e a cultura, o desenvolvimento de debates sobre a origem das desigualdades escolares terão uma influência forte no

\footnotetext{
${ }^{10}$ GRÉMION, De Pierre Bourdieu à Bourdieu, p. 40-4.
} 
sentido de apresentar: (i) suas análises a respeito da origem das desigualdades quanto ao acesso e sucesso na universidade; (ii) uma análise sociológica elaborada a partir de certos princípios dos fundadores da sociologia - Durkheim, Marx e Weber, que devem, acrescente-se, serem vistos como Grémion os apresentou -; (iii) um estudo sobre a relação dos estudantes com a cultura que põe em relevo as determinações ocultas advindas da origem social para as desigualdades escolares (BRUNO, 2009, p. 14). ${ }^{11}$

De mais a mais, vinculada à análise da reprodução dos mecanismos de reprodução social, Les Héritiers é um bom exemplo de um modelo de trabalho que é claramente ligado à crítica política e social sem perder com isso o status de cientificidade: o intento dos autores era justamente o de avaliar a consonância do sistema de ensino com valores políticos, notadamente aqueles da democracia e da igualdade de acesso à educação superior, a partir de um tipo ideal de herdeiro, que era o estudante parisiense de Letras Clássicas e Filosofia, envolvido num ambiente prestigiosos no qual se encontra a riqueza cultural da universidade para cujo uso dispunha dos recursos (GRÉMION, 2005, p. 39-40). Esse aspecto recupera a crença que tinham os franceses de que as instituições escolares públicas eram o símbolo do afiançamento dos princípios republicanos e democráticos, de tal modo que as ideias progressistas significavam a ampliação da igualdade de possibilidades. Organizadas assim, o desempenhar das suas funções agiria no sentido da superação das assimetrias sociais que repousavam nas contingências de origem (SIDICARO, 2009, p. X).

Essa disposição que, em tese, acreditava-se permitir a superação das disparidades radicadas na origem, é caudatária das contribuições de Durkheim, o qual, em muitas de suas lições e obras, enfatizava a necessidade de a educação pública ser organizada de modo a promover a socialização dos princípios laicos e republicanos. No entanto, as análises de Bourdieu e Passeron demonstraram que estas instituições escolares, diferentemente do que se pensava, através da outorga de títulos e reconhecimentos educativos àqueles que pertenciam a situações culturais, sociais e econômicas privilegiadas, era um fator de fissura social no sentido da promoção de

\footnotetext{
${ }^{11}$ Recomenda-se ler as páginas anteriores desse texto, já que apresentam uma análise interessante sobre o percurso metodológico e produtivo, quanto às obras e a antecipação de algumas teses, tanto de Bourdieu quanto de Passeron, até chegar à elaboração de Les Héritiers.
} 
desigualdades. Porém, a análise conduzia a uma constatação contundente: tais desigualdades, antes de serem percebidas, eram camufladas e legitimadas por aqueles que estavam no pólo desfavorecido. Dessa feita, as instituições escolares não apenas eram fatores de desigualdades sociais, mas desempenhavam um papel de legitimação e reafirmação dessas desigualdades de origem, as quais, por sua vez, eram vistas sob a forma de dons e talentos naturais. Para realizar essa análise, os autores se centram num flanco da cultura. Como sugerem,

Se for verdade que escolha forçada das faculdades de ciências e de letras é uma manifestação da desvantagem escolar que está ligada aos sujeitos das classes inferiores e médias (até mesmo quando conseguem viver seu destino como vocação), se for verdade que os estudos de ciências parecem menos ligados à origem social e, enfim, se se aceita que é no ensino literário que a influência da origem social se manifesta mais claramente, parece legítimo ver nas faculdades de letras o terreno por excelência para estudar a ação dos fatores culturais da desigualdade diante da escola, cuja estatística, operando um corte sincrônico, revela o resultado: eliminação, relegação e atraso. $O$ paradoxo que se quer na verdade é que os que estão em maior vantagem cultural não exponham tanto a sua vantagem justamente lá onde são relegados pela ação de suas desvantagens. (BOURDIEU e PASSERON, 2014, p. 23)

Como demonstrava a análise dos sociólogos, a passagem pelas instâncias educativas formais consagrava os estudantes cujas precedências familiares, sejam elas culturais, econômicas ou sociais, colocava-os em situações vantajosas em face da ação escolar afirmada igualitária, a qual valorizava positivamente as sensibilidades, predisposições e conhecimentos que tais estudantes traziam de seus lugares de origem assim como de suas trajetórias prévias, em múltiplos aspectos coincidentes com os conteúdos e destrezas afirmados como novos para todos, muito embora já fossem possuídos por esses alunos. Como afirmam, "De todos os fatores de diferenciação, a origem social é sem dúvida aquele cuja influência exerce-se mais fortemente sobre o meio estudantil [...]" (BOURDIEU e PASSERON, 2014, p. 27), através da qual são definidas chances, condições de vida ou de trabalho totalmente diferentes. De fato, a escola 
transforma as assimetrias de origem social e cultural em desigualdades escolares. ${ }^{12}$ Nesse sentido,

Os estudantes mais favorecidos não devem somente ao meio de origem hábitos, treinamentos e atitudes aplicáveis diretamente às suas tarefas escolares; eles também herdam saberes e um saber-fazer, gostos e um "bom gosto" cuja rentabilidade escolar, por ser indireta, é ainda mais certa [...]. (BOURDIEU e PASSERON, 2014, p. 34)

Em outras palavras, a forma como as instituições escolares estavam organizadas claramente reforçava e reafirmava o valor das habilidades formadas no interior de âmbitos de convivência prévios, os quais eram fortemente dependentes do acesso à cultura. No sistema de educação, enquanto que para alguns a cultura escolar era idêntica à cultura familiar, para outros ela representava uma aculturação. Assim procedendo, sob a camuflagem da igualdade de acesso, as instâncias educativas reafirmavam o valor de conteúdos cujas posses estudantes econômica e culturalmente privilegiados já traziam consigo através de suas experiências culturais prévias. Desse modo, estabelecia-se um ciclo vicioso que contava com o reconhecimento daqueles que eram, ao cabo, vítimas dessa mesma estrutura.

Com efeito, o sistema escolar reproduzia e premiava valores cujas consequências exacerbavam as assimetrias sociais, sob a chancela de princípios orientados à valorização de capacidades intelectuais e interesses frente ao conhecimento. Ao invés de dirimir as desigualdades de origem mediante a igualdade formal (ou legal) de todos face ao conhecimento, os sistemas escolares tendiam a afirmá-las e transformá-las em castas, as quais, obviamente, reproduziam aquelas desigualdades que os estudantes traziam de suas experiências prévias à dinâmica escolar.

\footnotetext{
${ }^{12}$ Vasconcellos propõe uma interpretação de conjunto da obra de Bourdieu sugerindo o uso do termo capital cultural. Conforme tal autora, Bourdieu e Passeron, em Les Héritiers, "chamam a atenção para a relação entre o "capital cultural”, a seleção social e escolar. O conceito de capital cultural (diplomas, nível de conhecimento geral, boas maneiras) é utilizado para se distinguir do capital econômico e do capital social (rede de relações sociais). Os estudantes de classe média ou da alta burguesia, pela proximidade com a cultura "erudita", pelas práticas culturais ou linguísticas de seu meio familiar, têm mais probabilidades de obter o sucesso escolar. "O que Bourdieu demonstra é que existe relação entre a cultura e as desigualdades escolares: a escola pressupõe certas competências que são de fato adquiridas na esfera familiar" (Baudelot, 2002)" (VASCONCELLOS, ano, p. 79-80).
} 


\subsection{Les Héritiers e Le Métier de Sociologue: um novo paradigma}

Quando se fala aqui que Les Héritiers representou o surgimento de um novo paradigma, deve-se entender tal afirmação especialmente em dois sentidos: primeiramente no sentido atribuído ao termo por Kuhn, pelo que se supõe que tenha representado, uma revolução científica a qual culminou no abandono das teorias hiperfuncionalistas para a explicação sociológica e se encaminhou para perspectivas mais críticas e menos positivistas. Calcadas em análises predominantemente balizadas por entrevistas, questionários e dados estatísticos, as teorias de então estavam mais preocupadas em discorrer sobre os objetos, no sentido de externar parâmetros quantitativos, que pouco diziam a respeito da dinâmica interna do objeto em apreço. Quando se diz, então, que Les Héritiers representou uma mudança de paradigma, principalmente quanto à imagem decerto mais romântica e democratizante da escola, diz-se justamente que, com ela, as análises não se concentravam apenas na apreciação estatística dos dados empíricos, mas que, com e através deles, pronunciamentos de caráter qualitativo são estabelecidos. E é especial e notadamente por meio dessa análise qualitativa do material empírico que, no trabalho de Bourdieu e Passeron, a dinâmica interna do objeto é desvelada.

Em segundo lugar, deve-se ter em vista não apenas o abandono das teorias hiperfuncionalistas de cariz positivista, mas o aparecimento e a eclosão na direção de muitas teorias da dinâmica social que se estendem para onde o positivismo havia fracassado. Sendo assim, com Bourdieu e Passeron - particularmente na França, já que os trabalhos da Escola de Frankfurt, na Alemanha, e aqueles no âmbito da filosofia e da teoria da ciência, como os de Popper e os do próprio Kuhn -, iniciou-se algo como um movimento que conduziu a afirmação de teorias sociológicas frontalmente contrárias à concepção positivista da ciência social. No entanto, o método científico que deu vazão a Les Héritiers encontra sua formulação numa obra posterior, Le Métier de Sociologue. Como os autores explicam na introdução, a respeito da metodologia das ciências sociais, 
O objetivo dessa obra é exatamente definir sua forma e conteúdo. Um ensino da pesquisa que tenha como projeto expor os princípios de uma prática profissional e inculcar, simultaneamente, uma certa atitude em relação a essa prática, isto é, fornecer os instrumentos indispensáveis ao tratamento sociológico do objeto e, ao mesmo tempo, uma disposição ativa para utilizá-los de forma adequada, deve romper com as rotinas do discurso pedagógico para restituir a força heurística aos conceitos e operações mais completamente "neutralizados" pelo ritual da apresentação canônica [...]. (BOURDIEU, PASSERON \& CHAMBOREDON, 2002, p. 12)

Trata-se, é verdade, da proposta de novo modus operandi, que se caracteriza por alguns princípios os quais enraízam uma postura científica nos termos de uma ruptura com o senso comum e da construção do fato social. Esse dois elementos são adequadamente expostos por Bonnewitz (2003), para quem o senso comum é, nas óticas de Bourdieu, Chamboredom e Passeron, definido como o conjunto das opiniões ou crenças admitidas no seio de determinada sociedade ou de grupos sociais particulares, que são considerados como impostas a todo espírito racional, e que não deve influir na postura científica. O sociólogo deve, isso sim, afastar-se do senso comum, das representações que o indivíduo tem socialmente, como ideias, como juízos preconcebidos, de modo a fundar sua explicação em diferentes variáveis não percebidas pelos indivíduos (BONNEWITZ' 2003, p. 28). E, como ele sugere, há duas causas para essa ruptura:

Esta ruptura com o senso comum é duplamente necessária. Por um lado, em razão do modo de constituição das categorias de percepção do senso comum e, por outro lado, porque este fornece explicações não científicas para os fenômenos sociais. (BONNEWITZ, 2003, p. 29)

No final das contas, como se pode observar, predomina/persiste? o juízo de que os indivíduos são produtos sociais: as categorias de representação, a linguagem, os valores são resultados de dinâmicas sociais. E, para a análise científica, significa dizer que a linguagem encerra um vínculo social, já que está atrelada a uma concepção de mundo. É isso que querem dizer ao afirmarem: 
[...] na medida em que a linguagem corrente e determinadas utilizações eruditas das palavras banais constituem o principal veículo das representações comuns da sociedade, é sem dúvida uma crítica lógica e lexicológica da linguagem comum que aparece como a condição indispensável para a elaboração controlada das noções científica. (BOURDIEU, PASSERON e CHAMBOREDON, 2002, p. 24)

Nessa direção, os autores afirmam que o sociólogo deve ser prudente quando está diante de um relato por parte dos agentes, uma vez que, em primeiro lugar, as justificações dadas por eles são sempre incompletas no sentido de que a produção dos seus discursos é dependente das suas características sociais e, em segundo lugar, não há uma consciência, por parte dos indivíduos, dos determinismos que produzem os seus discursos. É a isto que chamam de princípio de não-consciência (BOURDIEU, PASSERON e CHAMBOREDON, 2002, p. 25-29). Com efeito, ainda um problema contingente reside no fato de ser o próprio investigador socialmente situado, de ter uma inscrição social como parte da sociedade.

Os autores, em clara filiação à tradição epistemológica de Bachelard, argumentam que o fato social deve ser, em primeiro lugar, conquistado contra a ilusão do saber imediato, de modo a romper (i) com o senso comum, e, nele, romper com as representações e pré-noções que determinam inclusive a linguagem e o meio social do pesquisador, e (ii) com a sociologia espontânea daí resultante, e, em segundo lugar, construído contra as pretensões exacerbantes do empirismo, em termos de rupturas epistemológicas. Nesse ângulo, afirmam,

[...] os conceitos mais capazes de desconcertar as noções comuns não detêm, em estado isolado, o poder de resistir sistematicamente à lógica sistemática da ideologia: ao rigor analítico e formal dos conceitos ditos "operatórios" opõem-se o rigor sintético e real dos conceitos que receberam a designação de "sistêmicos" porque sua utilização pressupõe a referência permanente ao sistema completo de suas interrelações. Por mais parcial e parcelar que seja um objeto de pesquisa, só pode ser definido e construído em função de uma problemática teórica que permita submeter a uma interrogação sistemática os aspectos da realidade colocados em relação entre si pela questão que lhes é formulada. (BOURDIEU, PASSERON e CHAMBOREDON, 2002, p. 47-48) 
Esse modo de entender a construção do fato social pressupõe especificamente a concepção de que o empirismo não dá conta da complexidade da questão científica. Considerando que o objeto da ciência é construído, entendem os autores que "nada se opõe mais às evidências do senso comum do que a distinção entre o objeto 'real', préconstruído pela percepção, e o objeto da ciência, como sistema de relações construídas propositalmente" (BOURDIEU, PASSERON \& CHAMBOREDON, 2002, p. 46). Nesse modo de entender, a definição de ciência não é dada por um domínio qualquer da realidade, mas nos termos do princípio epistemológico formulado por Weber, em Essais sur la Théorie de la Science, por meio do qual se rompe com o realismo ingênuo: não são as relações reais entre as coisas que constituem o princípio de delimitação dos diferentes campos dos saberes científicos, mas as relações conceituais entre problemas (BOURDIEU, PASSERON \& CHAMBOREDON, 2002, p. 45).

Assim sendo, um objeto de investigação pode ser construído e definido de acordo com um problema teórico, pelo que Bourdieu e Passeron rejeitam o que denominam de empirismo. Esse empirismo, como entendem, partindo principalmente da leitura de Popper, em The Logic of Scientific Discovery, exacerba o valor dos dados e da metodologia, em suma, do trabalho experimental até as últimas manipulações de laboratório, em detrimento da teoria. É assim que se entende a reivindicação do relevo da teoria, no lastro de Bachelard: o vetor epistemológico vai do racional ao real, e não do real ao racional, na direção do que se defende que sem a teoria, toda pesquisa carece de interpretação e significado (BOURDIEU, PASSERON e CHAMBOREDON, 2002, p. 48-52). Sugere-se, então, que não existe instrumento que não pertença a uma teoria, de forma que todo instrumento é parte de uma teoria em ação. Assim compreendidas, as técnicas não são neutras, mas integram uma determinada teoria, com um leque amplo de significações. Compreendê-las demanda que sejam criadas técnicas necessárias de controle metodológico. Para o caso de Les Héritiers, convém pontuar uma passagem significativa: 
Sempre que o sociólogo for inconsciente em relação à problemática implicada em suas perguntas, privar-se-á de compreender a problemática que os sujeitos implicam em suas respostas: nesse caso, estão preenchidas as condições para que passe despercebido o equívoco que leva a descrever, em termos de ausência, determinadas realidades dissimuladas pelo próprio instrumento da observação e pela intenção, socialmente condicionada, do utilizador do instrumento. (BOURDIEU, PASSERON e CHAMBOREDON, 2002, p. 56-57)

Claramente, trata-se de uma crítica ácida à concepção positivista largamente presente no modo como as teorias hiperfuncionalistas orientavam as suas pesquisas. Dificilmente tais teorias estariam em condições de desvelar os condicionamentos reprodutivos das desigualdades sociais no interior da própria dinâmica escolar. Nesse sentido, para dar conta de significar e construir hipóteses, os autores recorrem à descrição de Weber dos tipos ideais. Trata-se, nesse caso, de um recurso heurístico que permite a invenção de hipótese, de modo a se constituir num instrumento de compreensão privilegiado: "o tipo ideal permite medir a realidade porque se mede em relação a ela e define-se com precisão ao determinar precisamente a diferença que o separa do real" (BOURDIEU, PASSERON e CHAMBOREDON, 2002, p. 66). Assim, o tipo ideal funciona como um guia para a construção das hipóteses, sendo uma ficção coerente para que a ação seja comparada e medida. Nesse sentido,

A comparação orientada pela hipótese de analogias constitui não só o instrumento privilegiado do corte com os dados pré-construídos, que pretendem com insistências ser tratados em si mesmos e por si próprios, mas também o princípio da construção hipotética de relações entre as relações. (BOURDIEU, PASSERON e CHAMBOREDON, 2002, p. 66)

Dessas considerações e enviesados pelo racionalismo aplicado de Bachelard, os autores afirmam que as suposições e as hipóteses implicam numa teoria sistemática da realidade, o que se constata em Les Héritiers ao afirmarem a não democratização do acesso à educação superior e a reprodução das assimetrias sociais que antecedem a etapa formativa. Nesse modo de compreender, o critério de validade é dado justamente pela coerência de um sistema de provas, e este é medido pela consistência dos princípios 
implementados, pela extensão dos fatos tidos em conta e pela multiplicidade de consequências imprevistas. Dessa sorte, a probabilidade da hipótese não depende somente da força estatística: depende, isso sim, do sistema completo das proposições já estabelecidas (BOURDIEU, PASSERON e CHAMBOREDON, 2002, p. 83). Esse modelo, portanto, presente em Les Héritiers e em Le Métier de Sociologue, tem como elemento característico nodal o racionalismo aplicado, que, conforme consideram, por encontrar-se efetivamente na encruzilhada entre o realismo e o racionalismo, é o único capaz de restituir completamente a verdade da prática científica porque associa intimamente os valores da coerência com a fidelidade ao real (BOURDIEU, PASSERON e CHAMBOREDON, 2002, p. 83).

\section{Considerações Finais}

Les Héritiers é um marco na sociologia da educação que propõe, no pleno sentido de Kuhn, um novo paradigma para a pesquisa e produção sociológica. Através de pesquisas empíricas que manejavam as enquetes e os dados recolhidos, os autores da obra enviesaram uma conclusão muito distinta do otimismo até então professados quanto ao sistema de educação francês. É nesse sentido que se pode afirmar ser um trabalho que é claramente ligado à crítica política e social sem perder o status de cientificidade. Tal concepção de ciência, por sua vez, foi posta, clara e evidentemente, em Le Métier de Sociologue, obra na qual as principais qualidades do sociólogo consistem em romper com o senso comum e, ao mesmo tempo, construir o fato social, numa clara vinculação à epistemologia de Bachelard, que propõe a inversão do vetor: não é a teoria que determina o real, mas o real que determina a teoria.

A par disso e com o propósito de levar tal análise a cabo, propôs-se a organização do texto em três partes. A primeira delas foi arvorada na direção de tracejar as diferenças entre o projeto de Bourdieu e Passeron em relação àquele de Durkheim no que se refere à compreensão tanto da educação como da escola. Para Durkheim, a escola é uma 
instância institucional integradora e socializadora fundamental para a sociedade. Inversamente, embora os autores retomem a centralidade da escola nos mecanismos de reprodução das estruturas sociais, esta instituição é responsável por perpetuar as desigualdades pregressas dos estudantes por basear-se em critérios que resultam exacerbadores do privilégio cultural. Dessa forma, a escola nada mais faz do que avaliar a partir de elementos que já estão culturalmente implícitos em estudantes cuja vivência familiar permite que tenham acesso a ambientes requintados e formadores do bom gosto.

Na segunda parte, por sua vez, procurou-se recuperar as influências teóricas que estavam presentes no meio sociológico francês em meados do século XX. Em vista disso, recuperou-se os principais traços da sociologia francesa da educação, após a queda da influência da tradição durkheimiana até os anos que antecederam a produção de Les Héritiers. Deu-se especial atenção à corrente estrutural-funcionalista, que tem em Parsons seu mais renomado defensor. Parsons ofertou uma concepção de sociedade que implicava o exercício equilibrado de funções para a estabilidade e sobrevida social. À educação cumpriria, assim, a função de socialização e integração social, através da qual se formavam os agentes que, em igualdade de condições, disputariam as funções hierarquicamente mais nobres socialmente.

$\mathrm{Na}$ terceira parte, dividida em outras duas, explanou-se, em primeiro lugar, acerca das principais características teóricas e metodológicas de Les Héritiers. Nesse sentido, argumentou-se sobre os aspectos que favoreceram a recepção do livro, notadamente, a dimensão da estrutura intelectual que, como Grémion sugeriu, dialoga diversamente com Weber, Marx e Durkheim. Além disso, apontaram-se nessa parte algumas teses evidentes no interior da obra. Na segunda subparte, por fim, argumentouse sobre a concepção de ciência que se encontra radicada nas duas obras. O paradigma que se afirma estar em Les Héritiers é o modus operandi posto a manifesto em Le Métier de Sociologue. É uma concepção, conforme evidenciado, que rompe com o senso comum e, opondo-se ao empirismo, muito presente na metodologia positivista, propõe que o fato social seja construído. Dessa feita, estabeleceu-se uma vinculação entre as duas obras na direção da concepção de ciência. Além disso, embora Bourdieu e Passeron 
tenham se afastado a partir do início da década de 70, pode-se ver como claramente identitária das trajetórias individuais posteriores esse momento, tanto em relação à concepção de ciência, quanto no que diz respeito à formulação das categorias epistemológicas e sociológicas.

\section{Referências}

BARANGER, Denis. Entre le modèle et l'enquête: une rupture méthodologique dans La distinction. Présentation au colloque "Trente ans après La Distinction". Paris, 4-6 novembre 2010.

BONNEWITZ, Patrice. Primeiras Lições sobre a Sociologia de P. Bourdieu. Petrópolis: Vozes, 2003.

BOURDIEU, Pierre; CHAMBOREDON, Jean-Claude; \& PASSERON, Jean-Claude. A Profissão de Sociólogo. Preliminares Epistemológicas. Trad. Guilherme J. de Freitas Teixeira. $3^{\mathrm{a}}$. Ed. Petrópolis: Vozes, 2002.

BOURDIEU, Pierre; CHAMBOREDON, Jean-Claude; \& PASSERON, Jean-Claude. Le Métier de Sociologue. Préalables Épistémologiques. Paris: Paris: EHESS and Mouton, 1968.

BOURDIEU, Pierre \& PASSERON, Jean-Claude. Os Herdeiros: os Estudantes e a Cultura. Trad. Ione Ribeiro Valle e Nilton Valle. Florianópolis: Ed. Da UFSC, 2014.

BOURDIEU, Pierre \& PASSERON, Jean-Claude. Les Héritiers: les Étudiants et la Culture. Paris: Minuit, 1985.

BOURDIEU, Pierre \& PASSERON, Jean-Claude. Los Herederos: los Estudiantes y la Cultura. $2^{\mathrm{a}}$. ed. Bueinos Aires: Siglo XXI Editores Argentina, 2009.

BOURDIEU, Pierre \& PASSERON, Jean-Claude. A Reprodução: Elementos para uma Teoria do Sistema de Ensino. Rio de Janeiro: Francisco Alves, 2. ed. 1982.

BOURDIEU, Pierre. A Distinção. Porto Alegre: Zouk, 2007.

BOURDIEU, Pierre. Homo Academicus. Florianópolis: UFSC, 2011.

BOURDIEU, Pierre. Méditations Pascaliennes. Paris: Seuil, 1997.

BOURDIEU, Pierre. (Org. NOGUEIRA, Maria A.; CATANI, Afrânio). Escritos de Educação. $2^{\text {a }}$. ed. Petrópolis: Vozes, 1999. 
BRUNO, Alain. Pierre Bourdieu \& Jean-Claude Passeron: Les Héritiers, Les Étudiants et la Culture: un Renouveau de la Sociologie de l'Éducation. Paris, Ellipses, 2009.

CUNHA, Maria Amália A. Sociologia da Educação. Belo Horizonte: Editora UFMG, 2010.

DURKHEIM, Émile. Educação e Sociologia. 4ª Ed. Petrópolis: Vozes 2011.

DURKHEIM, Émile. As Regras do Método Sociológico. São Paulo: Martins Fontes, 2007.

DURKHEIM, Émile. A Educação Moral. Petrópolis: Vozes, 2008.

DURKHEIM, Émile. L'Éducation Morale. Paris: Éditions Fabert, 2005.

DURKHEIM, Émile. O Ensino da Moral na Escola Primaria. Novos Estudos Cebrap, 78:61-75, 2007.

GRÉMION, Pierre. De Pierre Bourdieu à Bourdieu. Études 1 (tome 402), p. 39-53, 2005. Disponível em: www.cairn.info/revue-etudes-2005-1-page-39.htm. Acessado em 26/07/14.

KUHN, Thomas. A Estrutura das Revoluções Científicas. São Paulo: Ed. Perspectiva, 1978.

LALLEMENT, Michael. História das Idéias Sociológicas. De Parsons aos Contemporâneos. $2^{\text {a }}$ Ed. Petrópolis: Vozes, 2004.

MOUNIER, Pierre. Bourdieu, une Introduction. Pocket: Paris, 2001.

NOGUEIRA, Maria Alice. A Sociologia da Educação do Final dos Anos 60/Início dos Anos 70: o Nascimento do Paradigma da Reprodução. Em Aberto (Brasília), Ano 9, nº. 9, n. 46, p. 49-58, Abr./Jun., 1990.

PARSONS, Talcott. Essays in Sociological Theory. Revised Edition. New York: Simon and Schuster, 2010.

PASSERON, Jean-Claude. De El Oficio del Sociólogo a El Razonamiento Sociológico: entrevista a Denis Baranger. Revista Mexicana de Sociología (Universidad Nacional Autónoma de México), Vol. 66, nº. 2, p. 369-403, Apr./Jun., 2004.

ROBBINS, Derek. The Need for an Epistemological 'Break'. In: GRENFELL, Michel \& JAMES, David. Bourdieu and Education: Acts of Practical Theory. Bristol, PA: Falmer Press, 1998.

RODRIGUES, Alberto Tosi. Sociologia da Educação. 5. ed. Rio de Janeiro: DP\&A, 2004.

SIDICARO, Ricardo. La Sociología según Pierre Bourdieu. In: Bourdieu, Pierre \& PASSERON, Jean-Claude. Los Herederos: Ios Estudiantes y la Cultura. $2^{\mathrm{a}}$. ed. Buenos Aires: Siglo XXI Editores Argentina, 2009.

STEINER, Philippe. La Sociologie de Durkheim. Paris: Éditions La Découverte, 1994.

VALLE, Ione Ribeiro. Por que ler Os herdeiros meio século depois? In: BOURDIEU, P.; PASSERON, Jean-Claude. Os Herdeiros: os Estudantes e a Cultura. Trad. Ione Ribeiro Valle e Nilton Valle. Florianópolis: Ed. da UFSC, 2014.

VALLE, Ione Ribeiro \& RUSCHEL, Elizete. Política Educacional Brasileira e Catarinense (1934-1996): Uma Inspiração Meritocrática. Revista Electrónica de Investigación y Docencia, v. 3, p. 73-92, 2010. 
VANDENBERGHE, Frederic. The Real is Relational: an Inquiry into Pierre Bourdieu's Constructivist Espistemology. Sociological Theory, v. 17, p. 32-67, 1999.

VASCONCELLOS, Maria Drosila. Pierre Bourdieu: A Herança Sociológica. Educação \& Sociedade, ano XXIII, nº. 78, p. 77-87, abril/2002.

WACQUANT, Loic. Durkheim e Bourdieu. A Base Comum e suas Fissuras. Novos Estudos, n. 48 , p. 29-38, julho, 1997.

WEBER, Louis. Les Héritiers et La Reproduction dans les Débats des Années 60-70.

Savoir/agir, n 17, Éditions du Croquant, p. 21-32, septembre, 2011. 